\title{
Environmental costs of hydropower plants
}

\author{
T. Komatsu ${ }^{1}$, H. Gotoh ${ }^{2} \&$ M. Takezawa ${ }^{2}$ \\ ${ }^{1}$ JP HYTEC Co. Ltd., Japan \\ ${ }^{2}$ Department of Civil Engineering, College of Science and Technology, \\ Nihon University, Japan
}

\begin{abstract}
The balance between human activity and the environment has been destroyed for some time because of rapid development in all parts of the world. The coexistence of development and the environment is achieved by technical and economic approaches. The technical approach takes into account such factors as air pollution measures, conserving energy, and recycling resources, while the economic approach accounts for the costs of environmental disruption and providing safeguards such as wildlife conservation and management plans. The economic development of Japan in the 1950s required substantial electric power. As a result, environmental and industrial pollution increased. The economy of Japan reached a new high in the 1960s, and the generation of electric power was overtaken by thermal power; which in turn was superseded by natural gas and atomic power following the energy crisis of the 1970s. The Japanese economy was depressed during the 1990s, but has recently shown signs of a gradual recovery. Accordingly, the demand for electric power has increased over recent years. The energy sources that will replace oil in the future are atomic power, natural gas, and wind power. Hydropower stations discharge only minor carbon dioxide, and are therefore better for the environment than atomic and natural power stations. The environmental cost of the development of hydropower stations is discussed in this paper.
\end{abstract}

Keywords: hydropower station, environmental cost, environmental consumption $\operatorname{tax}$.

\section{Introduction}

Prior to the industrial revolution, societies made good use of natural energy resources such as wind, water, and fire. Coal was used as the primary energy 
source during the industrial revolution, but was displaced by oil in the middle of the $20^{\text {th }}$ Century. The demand for electric power in Japan has steadily increased since the 1960s with continued economic development. The quantity of electric power generated in Japan in 2002 was about 1 trillion $\mathrm{kWh}$ [1], which is about 10-times the production in 1965. Although hydropower stations were actively constructed in Japan prior to the $1960 \mathrm{~s}$, thermal power stations were only constructed following the 1960s when the demand for energy increased with ongoing industrial development. The dominance of hydropower over thermal power was reversed in the 1960s. As a result, environmental pollution from flue gas has occurred from time to time. Since the highlight of Japan's environmental and energy legislation concerning flue gas control was enacted in 1962, the antipollution basic measure law was enacted in 1967, and the air pollution control law enacted in 1968. Moreover, the water pollution control law and laws concerning waste treatment and cleanup were enacted in 1970, and the Environment Agency of Japan was established in 1971.

The first global oil crisis occurred in 1973, and the strengthening of environmental impact reviews for power plant sites was determined by the Ministerial Council of the Ministry of International Trade and Industry of Japan in 1977. The second oil crisis developed in 1979, the same year in which an accident occurred at the Three Mile Island Nuclear Power Plant in the USA. In Japan, laws concerning the efficient use of energy were enacted in 1979, and guidelines concerning environmental impact assessment were determined by cabinet in 1984. The Environmental Impact Assessment Law of Japan was enacted in 1997 and enforced in 1999. We have reached a point where demand for electric power continues to increase at the same time that environmental controls are becoming increasingly rigorous.

\section{Energy resources}

Most of the energy generated by thermal power is presently supplied from coal, oil, and natural gas, however, there is global concern for the sustainability of these resources. Sustainable energy sources are currently being considered because of apprehensive concerning the marked environmental effect of thermal and atomic power.

Renewable energy sources include hydropower, wind power, solar power, and geothermal energy. Hydropower is the best source of sustainable energy and is a time-proven technology. The energy base for Japan in the late $19^{\text {th }}$ Century was coal, while the new energy sources of the $20^{\text {th }}$ Century were electric power and oil, which were managed by private businessmen. The first hydroelectric station in Japan was established by the Miyagi Spinning Factory in Tohoku District in 1888, with the first commercial hydropower business being the Keage Hydropower Station, which began operation in Kyoto during 1891. A nationwide company was established in 1939 by investors in 33 private companies and divided into nine electric companies in 1951. In addition, the national company J-Power was established in 1952 to undertake large-scale developments [2]. 
Prior to 1960 , the main energy sources in Japan were hydropower and thermal power, with hydropower generating $72 \%$ of energy in 1955 and thermal power $28 \%$; however, by 1960 hydropower generation had fallen to $43 \%$ of the national total, and thermal power increased to $57 \%$. Power generation changed again with the introduction of atomic energy, and by 1985, hydropower generated just $14 \%$ of the national energy production, thermal power $38 \%$, and atomic power $48 \%$ [3]. Electricity consumption had been increasing rapidly over this time, and the primary energy supply within Japan reached $543,557 \times 10^{10} \mathrm{kcal}$ in 2002, up from $168,910 \times 10^{10} \mathrm{kcal}$ in 1965 . The primary energy supply per head of population was $42.65 \times 10^{6} \mathrm{kcal}$ in 2002 , up from $17.19 \times 10^{6} \mathrm{kcal}$ in 1965 . The population of Japan was $127,435 \times 10^{3}$ in 2002 , up from $98,275 \times 10^{3}$ in 1965 [4]. The demand for electric power in Japan increased from about 150 billions $\mathrm{kWh}$ in 1965 to about 1 trillion $\mathrm{kWh}$ in 2002.

The contribution of hydropower was $10.6 \%$ of the national energy supply in 1965 , but had dropped to $3.3 \%$ in 2002 . Thus, the production of hydropower has decreased over time as energy production has increased from new power sources such as nuclear power, natural gas, and wind. Energy generation in Japan during 2002 was sourced from coal $(19.3 \%)$, oil $(50.7 \%)$, natural gas $(13.7 \%)$, atomic power (11.7\%), hydropower (3.3\%), and other sources (1.3\%) [5].

A study of the environmental and social effects of hydropower was conducted over a five year period (1995-2000) by government regulatory organizations, research organizations, and utility companies from six member countries (Canada, Finland, Japan, Norway, Spain, and Sweden); 112 international experts from 16 different countries participated in associated meeting and workshops [6]. The study noted that the environmental and social impacts of hydropower projects differ markedly from one project to another, and concluded that despite controversy related to a few projects, hydropower in general presents major environmental advantages because it is the largest contributor to the reduction of greenhouse gases in the electricity sector.

Recently, Dr. Mike Sale and Dr. Chuck of ORNL's Environmental Sciences Division explored the issues involved in developing hydropower resources in the U.S.A [7]. The primary questions of their discussion are as follows. Why is hydropower important to the United States? What is the status of the nation's hydropower resources? How will hydropower be replaced if it is lost? In addition to producing clean power, what are other environmental benefits of hydroelectric dams? What are the adverse environmental impacts of hydropower projects? Can these environmental problems be solved? What are some other examples of mitigation? What other conflicts and issues arise in hydroelectric development? How do you put a value on environmental resources? Are there special hydropower issues in other parts of the country? How many projects are you concerned with in the Pacific Northwest and in California? What kind of research is the laboratory doing in support of environmental mitigation for hydropower projects? Do you have a good example of a case where this balancing was done successfully? Why did the fish and wildlife agencies challenge you? What specific studies are being done on environmental mitigation for hydropower? Who is working with you on quantifying the costs of 
environmental mitigation? How are environmental impact statements prepared for hydropower projects? What are the worst problems faced by developers and operators of hydropower facilities? What's the bottom line? We looked several matters that claim our attention as follows. Dr. Mike Sale considers that the energy of flowing water is the most readily available, renewable, and clean domestic source of electricity that we currently possess. It is available in most parts of the USA that have high rainfall and mountainous areas, and in terms of total production, hydropower is the USA's leading renewable energy resource. Moreover, Dr. Mike Sale considers that reservoirs generated by hydropower projects have a significant recreational value, as they are extensively used for fishing, boating, water skiing, and swimming. Such lakes offer expanded habitats for fish, ducks, geese, pelicans, eagles, and ospreys, as well as providing storage for water supplies and aiding in the control of floods and soil erosion. Recreational opportunities almost always increase in areas where hydropower is developed. In terms of negative impacts, Dr. Chuck Coutant details that a river habitat is generally replaced by a lake habitat because most hydroelectric projects involve the construction of dams. Thus, habitats on land and in water are destroyed or altered by the impoundment of rivers. There are sound arguments for and against the construction of hydroelectric power stations. And the bottom line is that good research conducted hand-in-hand with hydropower developers and equipment suppliers can lead to standardized power plant designs to protect the environment and streamlined licensing actions to encourage the most appropriate hydropower development.

The contribution of hydroelectric power output in selected countries in 2002 was as follows: France $11 \%$, Canada $58 \%$, China $17 \%$, Russia $18 \%$, Japan $8 \%$, USA $6 \%$, Italy $14 \%$, UK $1 \%$, and Germany $4 \%[8]$.

\section{Environmental impact assessments and environmental costs}

The system of environmental impact assessment first developed in the USA in 1969 is now used in many parts of the world. Environmental impact assessment was introduced for public works in Japan in 1972, and is a formal process for evaluating the likely possible risks or effects on the environment of a proposed activity or development. The purpose of the Environmental Impact Assessment Law of Japan enacted in 1997 is to ensure that proper consideration is given to environmental protection issues related to development projects, and ultimately to ensure that present and future generations enjoy healthy and culturally rewarding lives. The environmental factors considered in an environmental impact assessment are air pollution by dust and other material, noise, vibration, water pollution by dirt and other sediment, topography and geology, animal and plant communities, the ecosystem, the landscape, the contact between of human and nature, the environment of such contact, and industrial waste. This law in Japan involves a relative assessment that is carried out by evaluating the opinion of the project developer in terms of whether the environmental impact can be avoided or reduced. 
The muddy water generated by the excavation of dams and the washing of concrete aggregate was a major environmental issue in the 1960s, as well as water shortages in areas downstream of sites of dam construction. As a result, the costs involved in financial and other forms of compensation began to be factored into developers' budgets. For example, fish were protected by improvements in water quality, and fishing has been possible in certain areas since the 1970s. The Japanese Government has made environmental impact assessment compulsory for hydropower station since 1977. Assessments of landscapes, animals, and plants were added to the legislation in the 1980s. Basic environmental law was adopted in 1993, while a basic environmental plan was formulated in 1994. Laws concerning the preservation of wildlife destined to become extinct, the utilization of recycled resources, waste treatment and cleanup, and the promotion of recycling were enacted in the 1990s. The Environmental Impact Assessment Law was enforced in Japan in 1999, making Japan the last of the OECD countries to enact such legislation.

The environment is invaluable, but it is difficult to evaluate the social benefits of environmental improvement and the social loss involved with environmental degradation. Different methods of environmental cost accounting can be divided into three types: (1) internal environmental cost accounting, (2) external environmental cost accounting, and (3) environmental benefit-cost accounting [9]. The first type consists of environmental cost accounting in which currently realizable environmental protection measures are the main object of the accounting calculation; this is based on external costs that should be internalized in the next accounting period. The second type consists of environmental cost accounting in which potential technological environmental measures are the main objects of the accounting calculation; this is based on external costs that will not be internalized in the next accounting period. The third type consists of environmental benefit-cost accounting in which realizable environmental protection measures are the main object of the accounting calculation; this is based on all environmental impacts, integrating all environmental costs and benefit objectives. The first type is the simplest, but the objects of the accounting measurement are often too narrow to describe the entire reality of the environmental situation with which companies are confronted. The second type is better than the first in that it involves future potential environmental measures as its object of measurement; however, its focus is theoretically strictly limited to external costs that are to be internalized in future accounting periods and that are measurable in terms of monetary units. Therefore, this type of accounting does not cover all the environmental impacts for which companies are theoretically responsible. The third type of calculation covers all kinds of environmental impacts, as it is based upon, and depends on, a company's environmental objectives. This type of environmental cost accounting is therefore considered to be the best form of environmental accounting to date. 


\section{Case studies}

When the demand for electricity is low, a pumped storage facility can store energy by pumping water from a lower reservoir to an upper reservoir. During periods of high electrical demand, the water can be released back to the lower reservoir to generate electricity.

\subsection{Okinawa's pilot seawater pumped-storage power plant}

A pilot seawater pumped-storage power plant with a maximum output of $30 \mathrm{MW}$ was completed in 1998 in Okinawa Prefecture, Japan, at a cost of 32 billion yen. Numerous precious organisms on the verge of extinction inhabit the area of the plant and its environs. Environmental conservation measures were undertaken before construction, during the period of construction, and following the construction of the power plant in a natural green space.

The pilot seawater pumped-storage power plant was constructed in the northwest of the main island of Okinawa, facing the Pacific Ocean. The northwest area of the main island of Okinawa is called Yanbaru. This area has mountains of approximately $400 \mathrm{~m}$ in height that traverse from north to south. The subtropical forest of Yanbaru is composed of unique vegetation, with a variety of environments formed by both the intricate terrain and unique vegetation. Therefore, Yanbaru is home to numerous species of animals, including rare species and sub-species that are unique to Okinawa. Sixteen species of precious and endangered animals were found in a special natural reserve area surrounding the construction site, including four species of birds, two species of mammals, six species of amphibians, three species of crustaceans, and one species of insect. The vegetation of the construction site is either secondary forest or natural broadleaf evergreen forest. Within this area are many plant species, including many species that are native to Okinawa and that naturally grow wild.

The Yanbaru area is covered with a thick layer of special soil named Kunigami-Mahji (commonly called red-soil), which has a $\mathrm{pH}$ of 4-6. Red-soil is easily eroded by rainfall into the sea and quickly sinks to the seafloor because of its high specific gravity (2.6-2.8). Red-soil can seriously damage coral reefs. Prior to construction of the pilot seawater pumped-storage power plant, conservation measures were taken with respect to precious animals to ensure that these animals would be able to independently migrate from the construction site to safe areas.

Periods of heavy rainfall are common in Okinawa, and tend to produce a great amount of muddy water. Therefore, a sedimentation pond and a chemical treatment plant were constructed in association with the power plant.

Environmental monitoring was carried out during the construction period (1990-1997) to assess both the impact of the construction on the surrounding environment and the effectiveness of the various conservation measures. The monitored fauna included amphibians, reptiles, land animals, water creatures, coral, and birds, as these creatures were most affected by construction because of 
their inability to readily migrate. Environmental monitoring has continued following the completion of construction (1998-2003). Additional postconstruction monitoring items are vegetation, marine creatures, and atmospheric salt content. The disposal area was improved to create a new natural space where wild creatures live in symbiosis and in which people can interact with nature while enjoying its power and mystery. The total environmental costs of the seawater pumped-storage pilot power plant were 1650 million yen, as shown in Table 1. The ratio of environmental costs to the total construction cost was $5 \%$.

Table 1: Environmental costs of the pilot seawater storage pumped-storage power plant.

\begin{tabular}{|l|l|l|}
\hline Item & Costs (million yen) & Contents \\
\hline Greening & $220(13 \%)$ & $\begin{array}{l}\text { Greening of construction } \\
\text { area } \\
\text { Management }\end{array}$ \\
\hline Water quality & $350(21 \%)$ & $\begin{array}{l}\text { reservoir of turbid water } \\
\text { drainage facilities } \\
\text { protect film of sediment } \\
\text { yield } \\
\text { measurement of water } \\
\text { quality }\end{array}$ \\
\hline Animals & & $\begin{array}{l}\text { Monitoring } \\
\text { Safeguard and movement }\end{array}$ \\
\hline New natural space & $790(48 \%)$ & $\begin{array}{l}\text { Arrangement of garden } \\
\text { plant } \\
\text { Development of ground } \\
\text { Waterway, bridge, road, etc. }\end{array}$ \\
\hline Total & $290(18 \%)$ & \\
\hline
\end{tabular}

\subsection{Hydropower plant extensions at Okutadami and Otori [11]}

The 2004 output of the hydropower plant built more at Okutadami and Otori, Japan, was $287 \mathrm{MW}$; this contributed to a reduction in carbon dioxide emissions compared to other energy sources. The original dams at Okutadami and Otori were completed in 1960 and 1963, respectively, with a total construction cost of 63 billion yen. The area surrounding the reservoirs has been designated a quasinational park. Endangered birds live in this area, including golden eagles and goshawks. Measures of economical preservation for the project were natural landscape, precious birds, noise and vibration, water quality, by-products of construction, restoration of swamp and marsh areas, protection of fishes whose route was interrupted by the dams, and the introduction of environmental management. These environmental costs were about 6 billion yen, which represents $9 \%$ of the total construction cost of 63 billion yen (Table 2). 
Table 2: $\quad$ Environmental costs for the Okutadami and Otori projects.

\begin{tabular}{|l|l|l|}
\hline Item & Cost (million yen) & Contents \\
\hline Natural landscape & $970(16 \%)$ & Beautification Greening \\
\hline Water quality & $1,450(24 \%)$ & $\begin{array}{l}\text { Turbid water treatment } \\
\text { Pollutant protect film } \\
\text { Measurement of water quality }\end{array}$ \\
\hline Noise and vibration & $370(6 \%)$ & $\begin{array}{l}\text { Soundproof facility } \\
\text { Regulation of traffic } \\
\text { Regard of blast }\end{array}$ \\
\hline $\begin{array}{l}\text { By-product of } \\
\text { construction }\end{array}$ & $670(11 \%)$ & $\begin{array}{l}\text { Industrial waste treatment } \\
\text { Dehydrated soil }\end{array}$ \\
\hline Precious birds & $1,990(33 \%)$ & Investigation of birds \\
\hline Fishes & $310(5 \%)$ & Investigation of fishes \\
\hline Indirect cost & $310(5 \%)$ & \\
\hline Total & $6,070(100 \%)$ & \\
\hline
\end{tabular}

\section{Future trends in environmental costs}

The Environmental Impact Assessment Law of Japan was wholly enforced in 1999. The new method of environmental assessment introduced the scope system, additional items for examination and estimation, and introduced new aspects of estimation and examination following the completion of construction by developers examining the condition of the environment and predicting the nature of environmental conservation and environmental impacts. Consultation was arranged with locals and government departments concerned with developments regarding the fact that the preliminary report in the conventional method of assessment that did not consider external information in undertaking project planning.

The scope system determines what the major environmental concerns of the project, is the parties involved in the project, and the nature of information that is required from the developer. The additional items for examination and estimation included biodiversity, nearby natural areas, and greenhouse gas in addition to the existing items of the seven main pollutants and aspects of the precious natural environment. The new aspects to the estimation process include addressing evasion of environmental responsibilities and reducing environmental damage by assessing plans and introducing sound practices. In addition, the estimate of how the development is consistent with the environmental conservation policy is important.

Examinations following the completion of construction include an analysis of the uncertainties involved in the earlier predictions and the estimation. Also important in this regard is the management and the nature of announcements 
corresponding to items, the practices employed and the results following the completion of construction. The environmental costs of projects have been steadily increasing in recent years. Therefore, the application of the new environmental impact assessment law means that the development of new hydropower stations will be affected by predicted increases in the environmental cost of the investigation, conservation measures, monitoring during construction, and investigations following the completion of construction. The economic viability of future hydropower stations may have suffered with increased environmental costs, but this can be offset by improved design, the introduction of new technology, international requisitions, and reduced construction costs. The primary investment involved in constructing a hydropower station is large, but hydropower provides a stable return for a long time because the service life of a hydropower plant is long. In addition, the use of hydropower as domestic energy makes a large contribution to the reduction of carbon dioxide levels and thereby a reduction in the rate of global warming.

Therefore, the development of hydropower that can coexist with the natural environment depends upon the introduction of an economic measure such as a national grant or an environmental consumption tax. We need an environmental tax to deal with the global phenomena of environmental destruction and resource scarcity. It is necessary to reform our financial/tax policy so that the environmental costs that stem from our daily lives are built into the economy, ensuring a move in the direction of environmental protection and less dependency on non-renewable resources [12]. There is no single definition of environmental tax, and the term is often used in a vague way; however, there is general agreement on the purpose and function of such a tax, including: (1) to provide an incentive to lessen environmental burdens and preserve the environment, and (2) to establish a tool for preserving the environment via the use of tax revenue. To enhance the positive effects of a future environmental tax, it is important to avoid establishing a single rigid standard for taxable targets or tax rates, and instead consider tax returns and a revenue-neutral environmental tax with continuous and gradual increases in tax rates and the use of environmental tax revenues.

\section{Conclusions}

Hydropower is the only renewable energy technology that is presently commercially viable on a large scale. It has four major advantages over other energy sources: it is renewable, produces negligible amounts of greenhouse gases, is the least costly way of storing large amounts of electricity, and can easily adjust supply to the demand of consumers. The management of environmental impacts associated with hydropower projects has progressed considerably over the last twenty years as a result of environmental studies, monitoring of follow-up projects, and increased regulatory requirements. Experience gained worldwide in terms of improved project planning and design, as well as the development of comprehensive environmental mitigation programs, has helped avoid or reduce the severity of a large number of impacts 
typically associated with hydropower construction projects. Small-scale hydropower systems that have minimal negative environmental impact are also a strong potential energy source for the future. Finally, the strong relationship among the business, the citizen and the government for the environmental invention in the 21 st Century is demanded at present. A certain route of the sustainable life style is wanted by contributing voluntarily the environmental cost. The reasonable system that anybody can join must be constructed in order to connect the environmental sense of the citizen to the concrete action and translate the investment of the environmental preservation into reality.

\section{Acknowledgement}

We are grateful to J-POWER for kindly providing data of environmental costs.

\section{References}

[1] Japanese Agency for Natural Resources and Energy (ANRE). Energy 2003, http://www.atom.meti.go.jp

[2] History of Hydroelectric Generation in Japan, http://www.suiryoku.com/history/S.html

[3] The Kansai Electric Power Co. Inc., History of the Thermal Power Generation, http://www.kepco.co.jp/energy/fpac/history/

[4] The Energy Conservation Center, Summary of Energy and Economy Statistics 2004.

[5] ANRE, Outline of Development of Power Supply, 2004

[6] IEA, Environmental and Social aspects of Hydropower, http://www.ieahydro.org/ Environment/annex3.htm

[7] ORNL, Hydropower: Licensed to Protect the Environment, http://www.ornl.gov/info/ornlreview/rev26-34/hydmain.html

[8] TEPCO, Study of Environmental Energy, http://www.tepco.co.jp/custom/ Laplearn/world/fra01-j.html

[9] N. Miyazaki, Basic Types of Environmental Cost Accounting and Their Comparison, $\quad$ http://subsite.icu.ac.jp/ssri/Publications/SummaryFolder /J49Summaries /MiyazakiEng.html

[10] T. Komatsu, et al., Environmental conservation measures for construction of a power plant, Proc. of $1^{\text {st }}$ Int. Conf. on Environmental Exposure and Health, WIT Press, 2005.

[11] T. Komatsu, et al., Outline of the hydropower plant built more Okutadami and Otori, Electric Power Civil Engineering, No.288, 289, 2000. (in Japanese)

[12] JACSES, What is Environmental Tax? http://www.jacsesorg/en/ paco/envtax.htm 